\title{
La política exterior de la transición chilena desde sus fuentes internas*
}

\section{The Chilean Transition's foreign policy from its internal sources}

\author{
Cristián Fuentes Vera ${ }^{* *}$ \\ Universidad Central de Chile, Santiago, Chile
}

Recibido: 11 de junio de 2014. Aprobado: 26 de agosto de 2014.

\begin{abstract}
Resumen
La política exterior de la transición chilena es considerada una experiencia exitosa de reinserción internacional, en el contexto de un país pequeño, alejado de los centros de poder mundial y aislado políticamente por 17 años de dictadura. Sin embargo, parece equivocado separar la política externa de la política doméstica, pues se trata de una distinción formal que desprecia la importancia del cambio de régimen en la toma de decisiones, proceso determinado por fuentes internas tales como las características de la transición, la autopercepción que posee Chile sobre su rol en el mundo, el modelo económico, el papel de la Presidencia de la República, la influencia de las Fuerzas Armadas y la tradición diplomática.
\end{abstract}

Palabras claves: política exterior, fuentes internas, transición a la democracia.

\begin{abstract}
The foreign policy of the Chilean Transition (to democracy) is considered a successful example of international reintegration, in the context of Chile being a small country, far from the centers of world power and politically isolated due to seventeen years of dicta-

* Este artículo tiene relación con el proyecto de investigación "Política exterior de la transición chilena (1990-2012)", financiado por la Universidad Central de Chile (2013-2014).

** Facultad de Ciencias Políticas y Administración Pública, Universidad Central de Chile. Correo electrónico: crfuentes47@gmail.com
\end{abstract}


torship. However, it seems wrong to separate foreign policy from domestic policy, as it is a formal distinction that disregards the importance of regime change in the decision making process, a process determined by internal sources such as the characteristics of the transition, the self-perception that Chile has about its role in the world, its economic model, the role of the Presidency of the Republic, the influence of the Armed Forces, and the country's diplomatic tradition.

Keywords: foreign policy, domestic sources, transition to democracy.

\section{Introducción}

La transición democrática chilena (1990-2010) logró reinsertarse con éxito en el difícil mundo de la pos-Guerra Fría, transformando a un país pequeño, alejado de los centros de poder internacional y políticamente aislado por 17 años de dictadura, en una suerte de global trader (comerciante global) que, pese a su tamaño, emergió como un actor decidido a ser protagonista de la globalización triunfante. Esta experiencia, modélica para algunos, ha incitado el uso de la concepción del viejo realismo que separa la política externa de la interna, olvidando que esa distinción es meramente formal y que la mayoría de los temas tienen una dimensión interméstica ${ }^{1}$.

¿Por qué esta distinción? Aparte de un ambiente teórico demasiado dominado por el realismo clásico, los gobiernos de la Concertación de Partidos por la Democracia que dirigieron el proceso de transición, consideraron que el cambio de régimen político requirió acuerdos con la oposición de derecha que muchas veces se distanciaban de sus principios, en aras de asegurar la estabilidad y el crecimiento, sensibilidad que no era tal en un ámbito como la política exterior, donde el consenso era básico para viabilizar la actuación chilena ante el resto del orbe.

Pero el posicionamiento de comerciante global es demasiado economicista y está despojado de preferencias regionales, por lo que el análisis concertacionista oficial lo matiza con otras aproximaciones de naturaleza política, social y cultural más vinculadas al entorno vecinal latinoamericano, que serían igualmente válidas en una administración plural y de sello evidentemente pragmático.

1 Este concepto fue desarrollado en Estados Unidos para referirse a aquellas materias que contienen aspectos internacionales y domésticos que interactúan entre sí de múltiples formas (MacShane, 2003). 
Cualquiera sea el punto de vista elegido, parece tener mayor lógica pensar que la actuación chilena externa es el resultado de la interacción entre actores e instituciones de origen endógeno, cuyas relaciones se producen en el contexto de la hegemonía neoliberal vigente luego del fin de la Guerra Fría. Esta afirmación puede ser demostrada si identificamos el peso en la toma de decisiones de la política exterior en el período en estudio, adquirido por determinantes tales como las características propias de la transición, la autopercepción que posee el país sobre su rol en el mundo, el modelo económico, el papel de la Presidencia de la República, la influencia de las Fuerzas Armadas y la tradición diplomática.

Por ello, en el siguiente artículo intentaremos una breve aproximación desde las fuentes internas a la inserción internacional lograda durante la transición, modalidad que nos parece adecuada en función de establecer con mayor precisión el contorno y los efectos de un proceso tan trascendente para toda la sociedad chilena, como fue el tránsito de la dictadura a la democracia.

\section{Formulación de la política exterior de la transición chilena}

\section{Fuentes externas}

A pesar de la importancia de las fuentes internas en este estudio, es necesario precisar que los estímulos provenientes de un mundo sujeto a mutaciones profundas, de un contexto sudamericano donde el equilibrio estratégico tradicional había sido radicalmente modificado y de una democracia prevaleciente por vez primera, obligaron a la política exterior chilena a hacer un ejercicio particular de adaptación.

El sistema internacional de pos-Guerra Fría se caracterizó por la desaparición del antiguo esquema bipolar y por un capitalismo en su fase posindustrial, con nuevos actores, arenas, fenómenos transnacionales, espacios económicos integrados y la presencia de compañías multinacionales que representaban dos tercios del comercio global (Chakravarthi, 1996), reuniendo 500 de ellas a la mitad del PIB mundial (Pochmann, 2009). 
El Cuadro expone algunas de las dimensiones más importantes de la globalización y nos permite hacernos una idea del nuevo panorama internacional en el cual debía insertarse la democracia chilena recién recuperada:

Cuadro

Dimensiones de la globalización

\begin{tabular}{ll}
\hline Dimensiones & Descripción \\
\hline Tecnológica & $\begin{array}{l}\text { Revolución digital, microelectrónica con abundante disponibilidad y } \\
\text { costos decrecientes, informatización. } \\
\text { Cultural }\end{array}$ \\
$\begin{array}{l}\text { Cultura global, inglés como idioma universal, acceso masivo a } \\
\text { de un mismo planeta). }\end{array}$ \\
Comercial & Avance en la liberalización comercial, espacios regionales. \\
Financiera & Unificación y desregulación de los mercados. \\
Productiva & Producción en red. \\
Laboral & $\begin{array}{l}\text { Deslocalización. } \\
\text { Política }\end{array}$ \\
Medioambiental & Instituciones y regímenes mundiales, del estadocentrismo. \\
Migraciones & Calentamiento global, agujero en la capa de ozono. \\
Actividades delictivas & Movilidad transnacional masiva. \\
\hline
\end{tabular}

Fuente: Elaboración propia, Fuentes, 2013-2014.

Esta situación permitió la hegemonía del neoliberalismo, enfoque que interpretó la globalización como expresión de un capitalismo financiero desregulado; mientras que el modelo de integración regional fue sometido a una intensa crítica, quedando reducido a la esfera europea y a problemas como el volumen de la burocracia y la supuesta ineficacia del Estado de bienestar.

Por su parte, el término de la mayoría de las dictaduras en América Latina facilitó la configuración de democracias que, aunque con distintos grados de fortaleza institucional, han hecho viable ejercer por un tiempo prolongado libertades y derechos, la alternancia en el gobierno, la representación ciudadana y la ascensión al poder de sectores históricamente postergados. 
En 1985, Brasil y Argentina decidieron terminar con la rivalidad que los separaba en el Atlántico Sur, alterando el eje estratégico que definía las alianzas en Sudamérica, movimiento que dio origen al MERCOSUR (Mercado Común del Sur, esquema de integración formado por Argentina, Brasil, Paraguay y Uruguay) y que consolidó las bases de una plataforma de cooperación, que fue capaz de ir superando diferencias hasta involucrar al conjunto de la subregión en iniciativas más amplias como la UNASUR (Unión de Naciones Suramericanas).

Ante esta realidad, la transición chilena optó por una inserción más independiente en el escenario internacional, derivada de la continuidad en la apertura económica iniciada por el régimen militar. No obstante, se mantuvieron otras opciones y se evitó un alineamiento incondicional con la potencia dominante (Estados Unidos), surgiendo una política exterior que algunos califican como pragmática ${ }^{2}$.

El resultado fue una estrategia llamada “inserción múltiple”, que concebía a la política exterior como una palanca para el desarrollo y el crecimiento económico, objetivos que requerían suscribir acuerdos de libre comercio con los principales socios del país, conservando la autonomía en un marco no regionalizado.

\section{Fuentes internas}

La visión que Chile posee sobre sí mismo y su rol en el mundo

La formulación de la política exterior chilena obedece a fuerzas profundas ${ }^{3}$, tales como un carácter isleño motivado por la percepción de aislamiento al que lo remite el desierto de Atacama por el norte, el océano Pacífico por el oeste, la cordillera de Los Andes por el este y los mares australes por el sur. Esto hace que aunque haya logrado una inserción plena en la globalización, persistan rasgos culturales como la desconfianza hacia lo

2 Autores como Hugo Fazio Vengoa (2004, pp. 199 y 200) afirman que la política exterior chilena se ha sostenido en un pragmatismo económico y en un realismo político, que no han podido sobrepasar los estrechos horizontes comerciales.

3 Pierre Renouvin y Jean Baptiste Duroselle (2000, pp. 9 y 10) llaman "fuerzas profundas" a las condiciones geográficas y demográficas, los intereses económicos y financieros, las características mentales colectivas y las grandes corrientes sentimentales que han formado el marco de las relaciones entre grupos humanos y que, en gran medida, determinan su naturaleza. 
foráneo, especialmente cuando se trata de asuntos que van más allá de la economía, y de vecinos con los cuales se ha enfrentado históricamente.

Chile es distinto al resto de América porque fue la colonia más pobre del Imperio español y la primera en convertirse en una república estable después de la independencia, circunstancia que se debe al poder de los dueños de la tierra del valle central, quienes impusieron su cultura en la construcción de la sociedad nacional.

Estas condiciones explican la razón del 'excepcionalismo' chileno, así como la posición geográfica nos revela el origen de un sello "aislacionista" en nuestra política exterior tradicional, signos que constituyen un mecanismo de defensa frente a la diferencia percibida como agresión.

La visión precedente se sumó al entramado institucional, al neoliberalismo rampante y a las dinámicas políticas de la transición que exigieron el consenso con la derecha, para conformar una estrategia de acción exterior centrada en la economía y en alianzas tácticas con otros países afines (like minded countries), postergando la integración con Latinoamérica.

Tal perspectiva priorizó las relaciones con naciones pequeñas, democráticas, con economías de mercado e inquietudes sociales de cualquier lugar del mundo. En palabras de Augusto Aninat (comunicación personal, 10 de julio de 2013), primer director económico del Ministerio de Relaciones Exteriores (1990-1992), era preferible asociarse con: "unos demócratas de clase media y de centro-izquierda". Mientras que para Ángel Flisfish, director de Planificación de la Cancillería (2006-2009) y subsecretario del mismo Ministerio (2009-2010):

las apreciaciones hacia la región eran muy escépticas, por lo que fue bastante difícil la constitución de cualquier organización, al carecer de un pensamiento geopolítico y geoeconómico que separara las afinidades generales de los socios naturales efectivos o potenciales, los que no pueden ser otros que los países de América Latina (comunicación personal, 24 de julio de 2013).

\section{La transición democrática}

Luis Maira, exembajador en Argentina (2006-2010) y un experto en relaciones internacionales de dilatada trayectoria, nos dice que: 
las transiciones latinoamericanas se produjeron al término de la Guerra Fría y coincidieron con un momento muy desfavorable para las experiencias de izquierda y el pensamiento progresista. La primera en realizarse inmediatamente después de la caída del Muro de Berlín es la transición chilena, viviendo todas las restricciones y la estrechez intelectual de la etapa de apogeo del modelo neoliberal (comunicación personal, 8 de noviembre de 2013).

No obstante aquello, el peso de las circunstancias internas, o sea, el carácter del proceso transicional, estableció el marco en el cual se definió la política exterior, su naturaleza, alcances, opciones y trayectoria, más aun cuando se supone que las relaciones internacionales requieren un alto grado de coincidencias entre las fuerzas políticas y deben expresar la unidad del Estado.

Esas características fueron proyectándose en el tiempo hasta convertirse en un esquema de gobernabilidad, asentado según el ministro de la Secretaría General de la Presidencia, Edgardo Böeninger (1990-1994), en la democracia y la economía de mercado, un menor poder del Estado, cambios graduales, mayorías políticas capaces de gobernar apoyadas por la sociedad, compatibilidad entre crecimiento y equidad, partidos políticos fuertes y parlamentos sólidos, ausencia de corrupción, buen funcionamiento del Poder Judicial, seguridad ciudadana, respeto a las reglas del juego político y modernización del Estado (Böeninger, 1993, 1998 y 2014).

El cambio de régimen, en tanto, fue piloteado por una espesa trama de compromisos intra e interelites, en el cual se impusieron los intereses de grupos corporativos formales e informales ${ }^{4}$. Tales segmentos se fortalecieron usando los mecanismos disponibles en el ordenamiento constitucional, mientras los sectores democráticos se concentraron alrededor de la Presidencia de la República, fortificando todavía más sus funciones puesto que el Congreso se encontraba muy disminuido y se requería disciplina social, por lo que los cuadros técnicos y políticos de la coalición gobernante pasaron al Estado y la ciudadanía, que había cumplido un rol protagónico en la lucha contra el autoritarismo, fue desmovilizada (Fuentes, 2011).

Las administraciones democráticas promovieron reformas pero fue imposible realizar transformaciones de fondo, debido a la permanencia de enclaves autoritarios. Estos últimos eran los senadores designados, la inamovilidad de los comandantes en jefe de las Fuerzas Armadas, la composición y atribuciones del Consejo de Seguridad Nacional, el

4 Andrés Allamand, expresidente del partido de centro derecha Renovación Nacional, a propósito de las elecciones parlamentarias de 1993, llamó a los grupos que actuaban en paralelo a la institucionalidad "poderes fácticos"(los empresarios, los militares y el diario El Mercurio. Diario La Nación, 2006). 
sistema electoral binominal y los altos quórum para aprobar cambios constitucionales. A esto se debe agregar la presencia del general Augusto Pinochet como comandante en jefe del Ejército hasta 1998. La política exterior no escapó a tales condiciones, soportando a una derecha que aprovechó los mecanismos de vetos disponibles para orientar las iniciativas oficialistas según su conveniencia, resultado al cual se le llamó "consenso" (Fuentes, 2012). Alberto Van Klaveren, ex subsecretario de Relaciones Exteriores (20062009), agrega que a la construcción de este "consenso" también contribuyó la autoridad presidencial, porque "era muy difícil que un partido de Gobierno cuestionara una decisión del Jefe del Estado” (comunicación personal, 17 de junio de 2013).

Más aún, una de las ideas más relevantes de la transición fue la de democracia consociativa $^{5}$, para la cual la búsqueda del consenso constituía un factor incluso de supervivencia de la propia sociedad y del Estado. Sin embargo, para Van Klaveren (comunicación personal, 17 de junio de 2013), este diseño "no estuvo muy presente en relaciones internacionales, salvo la autocontención que hizo la izquierda, sobre todo el Partido Socialista, que se inhibió muchas veces de manifestar sus desacuerdos".

Hubo áreas de la política exterior como los asuntos territoriales donde los acuerdos básicos provenían de la dictadura (Van Klaveren, comunicación personal, 17 de junio de 2013). Aunque con matices, puesto que el respeto a los tratados y el principio de intangibilidad, que asegura la estabilidad de las fronteras nacionales, no ha impedido la apertura de espacios de negociación como el de Charaña con Bolivia, impulsado por el régimen militar en 1975. No obstante, los lazos con el vecindario variaron desde una manera de entenderlos que apenas superaba la creación de condiciones para hacer buenos negocios, a un impulso decidido a la integración en el inicio de la transición.

Esto permitió mejorar rápidamente las relaciones con Buenos Aires, despejando la totalidad de los diferendos limítrofes pendientes (24) e incrementando en forma sustancial los intercambios económicos, culturales, políticos y sociales. Con Perú, en tanto, se dio cumplimiento a las cláusulas todavía no materializadas del Tratado de 1929, apartando algunos de los impedimentos para mejorar los lazos con esa nación. Con Bolivia se intentó regularizar la relación bilateral sin que se pudiera concretar una fórmula sobre la salida al mar, principal escollo entre los dos Estados. No obstante, luego de un auspicioso inicio, otros temas coparon la agenda y la política exterior adquirió un tono economicista.

$5 \quad$ El destacado politólogo Arend Lijphart, en su libro Las democracias contemporáneas (1991), se inspira en los casos de Bélgica, Holanda y Austria para formular el modelo consociativo, pues las comunidades que integran esos Estados se obligan a respetar consensos mínimos, más allá de mayorías y minorías, ya que sin ello sería imposible la convivencia. 
Al contrario de Van Klaveren, aquí sostenemos que fue en la política exterior donde se concentró de manera más perfecta el ánimo consensual y las cortapisas de la transición, ya que la lejanía del tema para la opinión pública, el poder casi omnímodo del Presidente de la República, la influencia de actores y procedimientos burocráticos en la gestión cotidiana y la inspiración neoliberal de las autoridades, entre otros factores, ayudaron a construir un diseño para que el país se proyectara internacionalmente, acorde con la hegemonía intelectual y práctica vigente en ese momento histórico.

\section{Gobiernos de coalición}

Tomar decisiones en gobiernos unipartidistas o de coalición varía tanto en lo relativo a los actores intervinientes como en los mecanismos disponibles. La teoría demuestra que las coaliciones de gobierno existentes en los presidencialismos latinoamericanos inciden en la gobernanza y el quehacer político, al tiempo que conducen a un reordenamiento sustantivo en los sistemas partidistas (Reniu y Albala, 2012). En Chile se trataba de un extenso frente que logró aglutinar a la mayoría de los grupos opositores a la dictadura, salvo el Partido Comunista y otros sectores de extrema izquierda, y que fue capaz de ganar el plebiscito de 1988, ponerse de acuerdo en un programa único y triunfar en los comicios presidenciales de 1989.

Esta unión de 17 fuerzas políticas originó la Concertación de Partidos por la Democracia, alianza de amplio espectro que tuvo que conducir un complicado proceso de transición, aplicando a distintos ritmos iniciativas de democratización y elementos estabilizadores, hasta el triunfo de la derecha en las elecciones presidenciales de 2010.

A pesar del predominio del principio universalista y del restablecimiento de los vínculos diplomáticos con países de signo ideológico opuesto, algunos sectores del oficialismo persistían en criterios propios de la Guerra Fría, que generaron la necesidad de acordar criterios con los demás integrantes de la coalición.

Estos esquemas constituyeron una especie de "mínimo común denominador" que hacía factible la praxis del Ejecutivo, primando el respeto a los frenos y contrapesos del sistema político interno y el énfasis en la dimensión comercial de la política exterior. 


\section{Modelo económico}

El modelo de industrialización por sustitución de importaciones (ISI) que se usó como respuesta a la gran depresión de 1929 facilitó, entre otros avances, recuperar el crecimiento económico, construir la infraestructura fundamental que requería el desarrollo, crear riqueza y distribuirla más equitativamente, levantar industrias nacionales y establecer sistemas públicos de cobertura universal para atender las demandas de salud y educación de la población.

Ello se realizó a la sombra de un Estado cada vez más intervencionista y a costa de levantar fuertes barreras arancelarias para los bienes importados, medida que protegió a las economías locales, pero que requirió de un manejo restrictivo del tipo de cambio como fruto de la escasez crónica del dólar norteamericano y de otras divisas necesarias para el comercio internacional.

Tal esquema hizo posible un tipo de desarrollo inclusivo aunque débil, en el caso de un mercado pequeño como el chileno, pues nunca pudo superar la falta de capital, el déficit fiscal, los desequilibrios en la balanza de pagos, las devaluaciones periódicas y un alto nivel inflacionario.

El régimen militar reemplazó este esquema en 1975, al contrario del resto de la región, que lo mantuvo gracias a la deuda contraída en un momento de gran liquidez en el mundo de los años 70, situación que cambió radicalmente en la década siguiente, al restringirse el crédito. Con ello sobrevino una severa crisis que dio por finalizada la estrategia de crecimiento hacia adentro, debido a la imposición de los planes de ajuste ordenados por los organismos internacionales, medidas conocidas como el Consenso de Washington (Williamson, 1989).

Algunas condiciones fueron: i) disciplina fiscal; ii) iniciativa privada; iii) liberalización de los mercados; iv) apertura de la economía al exterior; y v) fomento de las exportaciones. Como la dictadura ya había realizado estos cambios, no le fue difícil incorporarlas a la Constitución de 1980, legando a la transición democrática un núcleo de políticas económicas blindadas por mayorías especiales que hacían imposible su reforma.

Así quedaron consignados principios esenciales como el derecho de propiedad, el rol subsidiario del Estado, un Banco Central autónomo y formado por consejeros sin responsabilidad política, y el poder irrestricto de un Ministerio de Hacienda que, mediante el control presupuestario, puede manejar el conjunto del gobierno. 
Para Carlos Portales,

aunque la apertura unilateral de la economía chilena realizada por el régimen militar fue bien recibida en muchos círculos económicos internacionales, la confianza del inversionista privado extranjero en la estabilidad del sistema económico solo se manifestó decididamente con el nuevo gobierno democrático, como puede apreciarse al comparar las cifras de inversión extranjera directa en el país que fue de 5.975 millones de dólares en 1981-1990 frente a 36.637 millones en 1991-2000 y 86.191 millones en 2001-2010 (2011, p. 7).

El Ministerio de Hacienda cumplió un rol determinante en toda la transición. Augusto Bermúdez, primer director de Planificación de la democracia (1990-1994), opina que

Patricio Aylwin estuvo muy cargado durante un buen rato hacia Alejandro Foxley (ministro de Hacienda entre 1990 y 1994), que era su mano derecha, sobre todo en temas económicos, ya que no sabía mucho de economía. Por eso, a Hacienda le preocupaba Estados Unidos, porque creía que era la vía para la internacionalización, era un tema más ideológico para ese Ministerio (comunicación personal, 23 de julio de 2013).

La naturaleza de la transición determinó que la Concertación se abstuviera de cualquier reforma sustancial que no contara con el apoyo de la oposición, pero robusteció aquellos aspectos que hicieran compatible los componentes de modelo con los compromisos de la democracia (Muñoz Gomá, 2007). El resultado fue un híbrido que mezcla los elementos más ortodoxos con el aumento del gasto social y el inicio de un sistema de protección más amplio, que pretendía moderar las inequidades propias del modelo original.

En el ámbito del comercio exterior, la orientación del período transicional fue conservar lo obrado hasta ese momento, o sea, la rebaja unilateral de aranceles y la liberalización multilateral, complementándolas con negociaciones bilaterales con sus principales socios, ya que poseía un intercambio comercial equilibrado con Europa, Estados Unidos y el Asia (más América Latina, que ofrecía un porcentaje menor, aunque con bienes de mayor valor agregado).

Varios criterios explican esta estrategia. Para Carlos Furche, ex director económico de la Cancillería (2006-2010), este era un tiempo de cambios internacionales dramáticos, en que daba la sensación de que solamente era posible el modelo capitalista en sus distintas variantes, existiendo la necesidad de consolidar la transición y garantizar una cierta perspectiva de crecimiento, para lo cual la apertura comercial también parecía algo razonable (2013), más aún cuando las megatendencias vigentes en el mundo estaban 
haciendo que las barreras artificiales al comercio se retiraran (A. Aninat, comunicación personal, 10 de julio de 2013).

El ministro de Economía del presidente Aylwin, Carlos Ominami (comunicación personal, 2 de octubre de 2013), piensa que el modelo anterior había colapsado a finales de la década de 1960, siendo la Unidad Popular un intento malogrado de reactivarlo.

Una economía abierta, que significara el fin de la protección a oligopolios ineficientes al interior del país, era una política mucho más progresista que la anterior, donde se sacrificaba la competencia y se hacía pagar a los chilenos precios altos por productos de mala calidad.

También existían razones prácticas, ya que un mercado pequeño y con una localización geográfica como el chileno, solo podía alcanzar un desarrollo dinámico y sostenible si lograba insertarse decididamente en la economía globalizada (C. Furche, comunicación personal, 27 de septiembre de 2013). Además, para el núcleo central de los gobiernos concertacionistas, la negociación de tratados de libre comercio como el de Chile con Estados Unidos era clave para anclar el modelo económico (A. Bermúdez, comunicación personal, 23 de julio de 2013).

Para Augusto Bermúdez, "el acuerdo con Estados Unidos ayudaba a anclar el modelo de apertura en Chile, lo que después se le ha llamado neoliberal". No obstante, puntualiza que:

En los primeros años el imperativo era mantenerse en el Gobierno. Hubo un acento en la política comercial, pero la reinserción se dio en varios frentes como el de los derechos humanos, la democracia, la cooperación no comercial con América Latina y las relaciones con Argentina (comunicación personal, 23 de julio de 2013).

Por el contrario, Augusto Aninat afirma que:

la transformación realizada durante las décadas precedentes era tan grande que no se podía revertir, más todavía cuando el país necesitaba pactos y hacer espacio para que los extremos pudieran volver a ser razonables y democráticos. No podíamos revisar el tema de las privatizaciones, tampoco podíamos volver al Grupo Andino, teníamos que ir hacia el comercio libre, pero no con el modelo doctrinario (comunicación personal, 10 de julio de 2013). 
No obstante, al inicio de la transición la experiencia de los principales funcionarios hizo que el espacio natural fuera América Latina. Los instrumentos disponibles eran los acuerdos de complementación económica, en el marco de la Asociación Latinoamericana de Integración (ALADI), los que facilitaban negociar la canasta arancelaria completa (R. Pizarro, comunicación personal, 16 de septiembre de 2013).

La inflexión se produce porque el Ministerio de Hacienda adquiere un poder trascendental, debido a la preocupación por mantener los equilibrios macroeconómicos, extendiéndose al resto del gobierno, en especial, a las negociaciones económicas con América del Norte. A principios de los 90, el presidente George Bush (padre) lanza la Iniciativa para las Américas, llamado que recoge de inmediato el ministro de Hacienda de la época (R. Pizarro, comunicación personal, 16 de septiembre de 2013).

Esta estrategia no es "pragmática", pues reproduce la política nacional que desde hace 40 años privilegia el libre mercado y las exportaciones de materias primas. Pragmática habría sido si existiera una política industrial como contrapeso, pero no hay ni un pequeño énfasis que favoreciera a los pequeños productores industriales, por lo que con una apertura económica sin protección, se reafirma que el país está destinado a producir y exportar recursos naturales (R. Pizarro, comunicación personal, 16 de septiembre de 2013).

Sin embargo, el clima predominante en esa época calificaba a la política industrial como un desastre y negaba la posibilidad que el Estado eligiera sectores ganadores. Entonces se decidió hacer una política industrial más horizontal que consistía en no elegir un sector, sino que contar con instrumentos que pudieran intervenir en el desarrollo. Además, fue necesario desmantelar el antiguo sistema de reintegro simplificado ${ }^{6}$, que en esa modalidad era un fuerte incentivo para el desarrollo de exportaciones no tradicionales (C. Ominami, comunicación personal, 2 de octubre de 2013), pero incompatible con el Acuerdo General sobre Aranceles y Comercio (GATT, por sus siglas en inglés).

Por su parte, llegar a acuerdo con MERCOSUR era difícil por su arancel externo común de más del 100\% y escalonado, cuando Chile andaba en el 15\% o 20\%, y parejo. A pesar de ello, la decisión de la administración de Patricio Aylwin era continuar con la apertura y Hacienda no podía imponer su opinión por el contrapeso que ejercía el Ministerio de Economía. Al calor del debate de aquellos tiempos, los negociadores con MER-

$6 \quad$ El sistema de reintegro simplificado consistía en la devolución del 10\% o del 5\% del valor FOB de las exportaciones menores (productos no tradicionales), según la Ley No 18.480 de 1985 (Ffrench-Davis, 2002). 
COSUR fueron llamados por Foxley "los últimos latinoides" (R. Pizarro, comunicación personal, 16 de septiembre de 2013).

Otro impedimento para que la alianza con la región lograra imponerse fue la falta de encadenamientos productivos, capaces de transformarse en un motor que afianzara el desarrollo de Chile y de arrastrar al resto de los países, papel que teóricamente debería cumplir Brasil pero que no ha sido posible ni siquiera para Uruguay o Argentina (C. Furche, comunicación personal, 27 de septiembre de 2013).

El país optó por una liberalización comercial con bajos niveles de regionalismo, correspondiendo a la Dirección Económica de la Cancillería llevar adelante las negociaciones conducentes a la firma de tratados de complementación económica y de libre comercio, aunque el Ministerio de Hacienda se reservó la decisión final sobre los temas más importantes. Sin embargo, podemos constatar que existe una diferencia entre el comercio y las inversiones, puesto que durante el período en estudio (1990-2010) Chile llegó a ser el tercer inversor en América Latina, detrás de México y Brasil. Esto puede explicarse porque el desarrollo y la estabilidad macroeconómica del país que permitieron la expansión interna del capital, toparon con las limitaciones propias de un mercado de 17 millones de habitantes, extendiéndose hacia su entorno regional por reunir las condiciones más favorables.

La necesidad de que la política exterior se basara en crear condiciones funcionales para un mayor crecimiento (C. Ominami, comunicación personal, 2 de octubre de 2013), se concretó en el gobierno del presidente Eduardo Frei Ruiz-Tagle (1994-2000) bajo la denominación de "inserción múltiple", siendo perfeccionado sucesivamente hasta convertirse en el "regionalismo abierto".

En realidad, esta noción se aleja tanto del significado asiático como de la interpretación cepaliana del tema, ya que, para las economías del Pacífico oriental, consiste en aperturas unilaterales concertadas (sin reciprocidad) más fuertes corrientes de cooperación, y para la CEPAL (Comisión Económica para América Latina y el Caribe), se refiere a un proceso de integración regional abierto al comercio mundial (Fuentes, 2012).

Como es evidente, el camino seguido por el país no corresponde a ninguna de estas definiciones, sino que a un diseño de liberalización sin preferencias regionales. Quizás, el complemento que podría haber transformado la conducta chilena en una nueva alternativa habría sido intensificar la cooperación política y, con el tiempo, contener o superar las diferencias comerciales. 
Para quien acuñó el término la realidad era un poco más simple, ya que se trataba de hacer una adaptación que permitiera seguir negociando acuerdos con todos nuestros socios importantes, sin renunciar necesariamente a la identidad latinoamericana en el ámbito simbólico y político (A. Van Klaveren, comunicación personal, 17 de junio de 2013).

\section{El factor militar}

Mientras el general Augusto Pinochet permaneció al frente del Ejército, las Fuerzas Armadas mantuvieron algunas de las prerrogativas que establecía el articulado original de la Carta de 1980, la cual concebía a los institutos castrenses como una suerte de suprapoder que vigilaba al resto de las instituciones. Las 54 reformas aprobadas en el plebiscito de 1989, los cambios democratizadores realizados con posterioridad y la salida del exdictador de la Comandancia en Jefe, permitieron que los militares volvieran progresivamente a sus tareas profesionales.

Formalmente, las Fuerzas Armadas no participaron en la formulación de la política exterior. La dictadura formó instancias en que cabía la injerencia de las ramas castrenses en términos de asesoría en política internacional, pero desde 1990 en adelante aquello se desactivó. La influencia se dio más como contribución a la configuración histórica de la cultura estratégica chilena, que deviene casi en un sentido común que las autoridades internalizan rápidamente, junto al actor principal en su configuración que son los militares, quienes disponen de escenarios diversos donde poder reafirmar los elementos de esa cultura estratégica, tales como las hipótesis bélicas (Á. Flisfish, comunicación personal, 24 de julio de 2013).

Las instituciones de la defensa conservaron la capacidad para imponer su doctrina, aparte de dispositivos que obligaban a los civiles a negociar los temas vinculados a sus intereses corporativos, a la seguridad nacional y al resguardo de las fronteras. Así, por ejemplo, los importantes recursos que la Ley Reservada del Cobre (10\% de las ventas de las empresas estatales) puso a su disposición y su influencia en la política interna, les otorgó la posibilidad de comprar sistemas de armamentos muy sofisticados, adquiriendo un poder de disuasión considerable que terminó por afectar las percepciones de amenaza de los países limítrofes, sobre todo en la zona norte.

Por otro lado, la permanencia de los objetivos y dispositivos de defensa insertos en la planificación estratégica concebida contra la probabilidad de una invasión peruana en 1974, que contemplaban a Arica como un punto de contención casi indefendible y 
a Iquique como la retaguardia desde donde se impulsaría una eventual contraofensiva, reforzados posteriormente por la negativa neoliberal a extender la zona franca hacia el extremo norte del país, prolongaron hasta el presente el atraso de la ciudad más septentrional de Chile.

Asimismo, fue imposible encontrar una solución a la mediterraneidad boliviana, no obstante el Ejército se mostró partidario de reponer la fórmula de Charaña (corredor soberano y compensación territorial ofrecidos por Augusto Pinochet en 1975). La oposición de la Marina y de amplios sectores de la opinión pública hizo que avanzar por este camino fuera de casi inadmisible consentimiento doméstico, con excepción del enclave sin soberanía al sur de Iquique, propuesto por el ex-Presidente Ricardo Lagos y que Bolivia rechazó.

\section{La tradición diplomática}

La tradición diplomática también sufrió variaciones durante la dictadura que se prolongaron en el período concertacionista, debilitándose aquellas orientaciones y prácticas originadas en la secular democracia chilena e intensificándose las de contenido autoritario y nacionalista.

El "espléndido aislamiento" (inspirado en el Imperio británico) y la "excepcionalidad" se potenciaron resueltamente como prueba de la inspiración conservadora de las autoridades, sirviendo de defensa ante la hostilidad de la comunidad internacional. Con mayor razón, cuando el régimen militar actuó con la lógica de la doctrina de seguridad nacional, que identificaba al comunismo como un enemigo externo e interno, a pesar de enfrentar con flexibilidad y pragmatismo diferendos con el entorno, gracias a lo cual pudieron evitarse conflictos armados simultáneos con los tres vecinos.

Ciertos intereses vitales históricos como el equilibrio del poder, el statu quo y los juegos limítrofes de suma cero guiaron la política exterior en esos años. Por el contrario, el respeto al derecho internacional y el protagonismo en los foros internacionales que caracterizaron a la antigua república, fueron considerados un asunto de expertos o una pérdida de tiempo.

En la raíz de esta actitud se encuentran las profundas modificaciones que el gobierno del general Augusto Pinochet realizó en la práctica diplomática, al combinar nacionalismo, realismo y bilateralismo en una estrategia que estimaba a la cooperación, la 
integración regional y a las instancias multilaterales como opciones ideológicas, inspiradas en visiones utópicas de las relaciones internacionales (Wilhelmy y Durán, 2003).

Los componentes centrales de la política exterior de la dictadura fueron el anticomunismo y el enfrentamiento ideológico (Wilhelmy y Durán, 2003), concebidos como una cruzada universal en la que Chile debía ocupar un lugar destacado. Sin embargo, sectores minoritarios prefirieron un mayor pragmatismo, concentrándose en los vínculos económicos e impulsando una política activa de relaciones con el Asia. Heraldo Muñoz le llamó a ambas posturas "pretoriana-ideológica y civil-pragmática”, respectivamente (1986).

Este aspecto se mantuvo e, incluso, adquirió un rol protagónico en la transición democrática, sobre todo con el ex-Presidente Eduardo Frei Ruíz-Tagle (1994-2000), quien tenía un interés especial que le llevó a impulsar el ingreso de Chile al APEC (Foro de Cooperación Asía-Pacífico, por sus siglas en inglés).

\section{La Cancillería}

Como la modernización del Ministerio de Relaciones Exteriores implicaba enfrentarse con los grupos corporativos, lo que redundaba en demasiados costos y pocos beneficios, los gobiernos de la Concertación prefirieron invertir recursos en una dimensión económico-comercial que les era más fácil dirigir. En la esfera política se generó una alianza con los diplomáticos de carrera dispuestos a garantizar ciertos niveles mínimos en la gestión administrativa.

La ausencia de voluntad política, los compromisos de la transición y los mecanismos e inamovilidades de diseño autoritario todavía vigentes ${ }^{7}$, impidieron poner al día un Ministerio de Relaciones Exteriores anticuado e ineficiente, guiado por una burocracia que aún opera según los supuestos establecidos por el pinochetismo, razón por la cual la gestión internacional de la democracia transitó por una parte de la Cancillería, básicamente la Dirección de Relaciones Económicas Internacionales (DIRECON), y por otras

7 La dictadura estableció que los cargos de planta son inamovibles, salvo por sumario administrativo o por una mala evaluación reiterada que casi nadie obtiene. Además, según el estatuto administrativo del Estado chileno la edad de jubilación es 65 años, pero es voluntaria por ser un derecho, y los gobiernos concertacionistas acordaron que los embajadores provenientes de la carrera debían mantenerse en sus cargos por lo menos hasta dicha edad, sin importar ser de exclusiva confianza del Presidente de la República, quien los puede remover cuando lo estime necesario. 
instituciones, lo cual permitió lograr éxitos importantes en el período (1990-2010). El excanciller Mariano Fernández afirma que:

durante este periodo ingresó gente sin ninguna competencia al servicio exterior y el tratamiento que le dio la dictadura quebró su voluntad, dejándolo como un conjunto de funcionarios obedientes, que si levantaban la voz eran postergados en su carrera o perdían el trabajo (M. Fernández, comunicación personal, 24 de octubre de 2013).

Del mismo modo, la verticalidad del mando ahogó cualquier posibilidad de deliberación y creatividad, descartando la elaboración de pensamiento propio y priorizando la praxis burocrática sobre la teoría. Asimismo,

...el mundo diplomático tiende a ser conservador y la Asociación gremial que los reúne fue siempre adversaria de la Concertación, manejada por grupos sin capacidad para contribuir a la modernización de la Cancillería, con la pretensión de cerrar el servicio para ese fragmento de profesionales de las relaciones internacionales, en un mundo donde los concursos abiertos por los cargos importantes son habituales" (M. Fernández, comunicación personal, 24 de octubre de 2013).

En todo caso, y pese a los variados esfuerzos realizados en estos años por encarar el tema, sigue pendiente la necesidad de modernizar el Ministerio de Relaciones Exteriores, pues dicha repartición pública mantiene un carácter fuertemente jerárquico, que se rige por criterios de antigüedad antes que por competencias. Tal situación demanda un urgente proceso de profesionalización del principal instrumento de ejecución de la política exterior de Chile, acorde con las condiciones imperantes en un escenario internacional sujeto a permanentes transformaciones.

\section{Hiperpresidencialismo y política exterior}

El reparto del poder característico de la transición y la existencia de autoridades unipersonales con demasiadas atribuciones, afectó también la generación y trayectoria de la política exterior, facultad exclusiva del Jefe del Estado según una Constitución marcadamente presidencialista como la de 1980.

Un recorrido por su texto nos indica que las atribuciones especiales del Presidente de la República son: "designar a los embajadores y ministros diplomáticos, y a los representantes ante organismos internacionales. Tanto estos funcionarios como los seña- 
lados en el artículo No 7 precedente, serán de la confianza exclusiva del Presidente de la República y se mantendrán en sus puestos mientras cuenten con ella". La Carta de 1980 suprimió la facultad del Senado de ratificar los nombramientos (Constitución de 1980, Arts. 8 y 32$)$.

Además, se establece que son funciones del Jefe del Estado: "conducir las relaciones políticas con las potencias extranjeras y organismos internacionales, y llevar a cabo las negociaciones; concluir, firmar y ratificar los tratados que estime convenientes para los intereses del país, los que deberán ser sometidos a la aprobación del Congreso conforme a lo prescrito en el artículo 54 No 1" (Constitución de 1980, Art.15).

En cuanto a la facultad presidencial de "conducir las relaciones políticas con potencias extranjeras y organismos internacionales", la expresión conducir significa "guiar o dirigir un negocio", diferenciándose de similar disposición contenida en la Carta de 1925 que comenzaba con el vocablo "mantener", el cual invocaba la idea de "conservar una cosa en su ser", poniéndose de manifiesto que el Presidente de la República es el verdadero rector de la política exterior del país y quien fija sus líneas directrices (Verdugo, Pfeffer y Nogueira, 1993).

En la Comisión de Estudios de la Nueva Constitución (Comisión Ortúzar) se plantearon diferencias en relación con el manejo de las relaciones exteriores por parte del Presidente de la República. Sergio Diez Urzúa consideró que:

La soberanía está limitada, ya que el Presidente de la República debe actuar en materias muy distintas de las propias de un tratado, como hacer una exposición ante un organismo internacional, o fijar el criterio del Gobierno ante organismos económicos internacionales, que tienen tanta o más importancia que la que tenía ayer un tratado. Por ello, cree que esa facultad debe quedar sujeta al consejo y conocimiento previo del Senado, y que la Comisión de Relaciones Exteriores de esa Cámara deberá tener más atribuciones que las que tuvo en el pasado, porque los problemas son cada día más complejos (Comisión Ortúzar, Acta sesión $\mathrm{N}^{\circ} 345$ ).

Enrique Ortúzar (presidente de la Comisión), por el contrario, dice que: "el Primer Mandatario es el conductor de las relaciones internacionales, aunque con la colaboración de un Ministerio de Relaciones Exteriores que cuenta con personal especializado, de una Comisión Consultiva de ex-Cancilleres y de un Consejo de Política Exterior". Además, expresa su inquietud ante la posibilidad de consagrar limitaciones a dicho manejo, salvo 
en lo que dice relación a los tratados o a algunos aspectos específicos (Comisión Ortúzar, Acta sesión $\mathrm{N}^{\circ} 345$ ).

Dicho criterio, que fue el que prevaleció, deja claro el espíritu ultrapresidencialista de la Carta de 1980 y la lógica autoritaria que la atraviesa transversalmente. Por si fuera poco, el manejo de las relaciones exteriores se caracteriza por la centralización administrativa de su gestión. Esta se manifiesta en la Ley No 19.175, Orgánica Constitucional sobre Gobierno y Administración Regional, aprobada ya en democracia, según el cual "los Ministerios se desconcentrarán territorialmente mediante Secretarías Regionales Ministeriales, de acuerdo con sus respectivas leyes orgánicas, con excepción de los Ministerios del Interior, Secretaría General de la Presidencia, de Defensa Nacional y de Relaciones Exteriores" (Art. 61).

Aquí se hace evidente la confusión entre los conceptos de descentralización y desconcentración, puesto que una función privativa, como son las relaciones exteriores con respecto al Presidente de la República, no puede ser delegada en otras autoridades pero sí organizada administrativamente de manera más autónoma.

La misma ley pone en manos del intendente la aplicación de la Ley de Extranjería y la adopción de las medidas necesarias para administrar los complejos fronterizos de la región, en coordinación con los servicios nacionales. A su vez, faculta al Gobierno Regional para participar en acciones de cooperación internacional, dentro de los marcos establecidos por los tratados y leyes respectivas, y le dota de las competencias necesarias en materia de ordenamiento territorial, para fomentar y velar por el buen funcionamiento de los servicios de transporte intercomunal, interprovincial e internacional fronterizo en la región, cumpliendo con las normas de los convenios internacionales respectivos.

En todo caso, con posterioridad a la entrada en vigencia de la Constitución de 1980 han aparecido diversas disposiciones que generan un cierto grado de descentralización. Tal es el caso de la Ley № 19.300, sobre Bases Generales del Medio Ambiente, que entrega a la CONAMA (Comisión Nacional del Medio Ambiente) la función de coordinar a los organismos competentes en materias vinculadas con el apoyo internacional a proyectos ambientales, y ser, junto con la Agencia de Cooperación Internacional, contraparte nacional en proyectos con financiamiento externo. También, la Ley No 18.695, Orgánica Constitucional de Municipalidades, contempla que las asociaciones de municipalidades puedan coordinarse con instituciones nacionales e internacionales, a fin de perfeccionar el régimen municipal. 
Asimismo, para Alberto Van Klaveren (comunicación personal, 17 de junio de 2013) el poder del Jefe del Estado en la toma de decisiones relativas a la política exterior es central, requiriéndose distinguir entre funciones críticas y de rutina. En tiempo de crisis dependen fundamentalmente de La Moneda y en las de rutina opera la Cancillería y su estructura jerárquica.

En el marco del presidencialismo chileno el ejercicio del mando es una prerrogativa de quien ocupa la primera magistratura (Á. Flisfish, comunicación personal, 24 de julio de 2013). También en cuanto al manejo de los recursos económicos, pues conseguir dinero por fuera del presupuesto regular depende de la aprobación del Presidente (A. Aninat, comunicación personal, 10 de julio de 2013).

Tales condiciones, unidas a la debilidad del Ministerio de Relaciones Exteriores, derivaron en una diplomacia presidencial sustentada en la mezcla de funcionarios públicos de confianza, profesionales y asesores externos. Esta situación redundó en la concentración excesiva del poder, la persistencia del secretismo, la falta de participación de la sociedad civil y de otros poderes del Estado, el alejamiento de los temas internacionales de las preocupaciones ciudadanas y la acción no siempre eficaz de una presidencia demasiado autosuficiente.

\section{Conclusiones}

Este artículo se sustenta en la importancia de las fuentes internas para explicar cómo se formuló la política exterior de la transición, relevando de manera tal el tejido institucional y político, que no solo constituye el contexto que genera las reglas para tomar decisiones, sino que las dinámicas que allí se despliegan conforman el tipo de estrategia empleada por Chile para insertarse en el mundo.

Esto no implica que las condiciones del sistema internacional en este período sean irrelevantes, sino que los fines, intereses y actores emanan del escenario doméstico. En el caso chileno, el esquema de vínculos políticos, sociales y económicos desarrollado en la transición tiene una relación estricta con la proyección externa del país.

El paso de la dictadura a la democracia fue dominado por los amarres del antiguo régimen y un balance de fuerzas insuficiente para el nuevo Gobierno, por lo que debió 
limitarse a reformas institucionales, medios y normas que facilitaran establecer una forma distinta de convivencia, concretando reformas a medida de los resultados de una negociación permanente que priorizó la continuidad por sobre la ruptura. Tal situación se materializó en arreglos y transacciones más que en cambios profundos, buscando una reinserción internacional acorde con las condiciones del proceso interno, aunque reconoció la necesidad de trabajar temas como los derechos humanos, la superación de los conflictos limítrofes, el acercamiento a la región y la apertura comercial, materia que con el tiempo llegó a ser el centro de la actuación internacional de Chile.

La política exterior de la transición se cristalizó en torno a un "consenso", pasivo e implícito por la ausencia de un debate abierto a la sociedad, que fue impuesto por ser concebido como requisito para articular la "política de Estado" que necesitaba el país. Ello impidió hacer explícita la trama de acuerdos que originaron esas orientaciones, así como el Presidente de la República jugó un papel rector en la toma de decisiones, debido a que el texto constitucional de 1980 le asignó funciones exclusivas en el ámbito internacional, todo lo cual concentró la toma de decisiones en un pequeño círculo alejado de la ciudadanía.

En conclusión, la política exterior fue históricamente construida, obedeciendo a un escenario desfavorable a innovaciones sustanciales, pues los gobiernos democráticos se encontraron con la necesidad de desmovilizar a la sociedad civil para hacer viable su programa y el neoliberalismo se encontraba en fase hegemónica, más aún cuando los partidos que habían integrado la Unidad Popular (1970-1973) debieron inhibirse de cualquier esfuerzo por imponer sus ideas.

Como consecuencia de estas dinámicas, el protagonismo se centró en la elite política y empresarial junto a académicos, especialistas y diplomáticos de carrera, a pesar de su falta de preparación y de provenir del antiguo régimen.

En suma, el sentido verdadero de la política exterior de la transición chilena es ser un reflejo casi exacto de la realidad doméstica, consignado como un dispositivo que filtra y procesa las demandas del entorno mundial. 


\section{Referencias}

Actas de la Comisión Ortúzar (s/f). Recuperado de http://www.bcn.cl/lc/cpolitica/actas_oficiales-r

Allamand: La soledad del corredor de fondo. (13 de mayo de 2006). Diario La Nación. Recuperado de http://www.lanacion.cl/noticias/pais/allamand-la-soledad-del-corredorde-fondo/2006-05-12/221342.html

Aninat, A. (10 de julio de 2013). Consultor internacional en asuntos económicos, Chile. Comunicación personal. Santiago, Chile.

Bermúdez, A. (23 de julio de 2013). Diplomático retirado. Comunicación personal. Santiago, Chile.

Böeninger, E. (1993). La gobernabilidad: un concepto multidimensional. Revista de Estudios Internacionales, 27 (105), 79-94.

. (1998). Democracia en Chile. Lecciones para la gobernabilidad. Santiago, Chile: Andrés Bello.

_____. (2014). Gobernabilidad: lecciones de la experiencia. Santiago, Chile: Uqbar Editores.

Constitución Política de 1980 (s/f). Recuperado de http://www.leychile.cl/ Navegar?idNorma $=242302$

Chakravarthi, R. (1996). Third World Network Features. Ginebra, Suiza: UNCTAD.

Dirección General de Relaciones Económicas Internacionales -DIRECON. (2014). Glosario de comercio internacional y definiciones contenidas en los acuerdos comerciales. Recuperado de http://www.direcon.gob.cl/glosario/

Fazio Vengoa, H. (2004). La globalización en Chile. Entre el Estado y la sociedad de mercado. Bogotá, Colombia: Universidad Nacional de Colombia.

Fernández, M. (24 de octubre de 2013). Consultor internacional, Chile. Comunicación personal. Santiago, Chile. 
Ffrench-Davis, R. (2002). El impacto de las exportaciones sobre el crecimiento en Chile. Revista de la CEPAL, 76 (abril), 143-160.

Flisfish, Á. (24 de julio de 2013). Director FLACSO-Chile. Comunicación personal. Santiago, Chile.

Fuentes, C. (2011). La política exterior de Chile 1990-2010. ¿Modelo a imitar o proceso inconcluso? En M. Fernández-Ramil, J. Ensignia y C. Fuentes (Eds.), Política exterior en el Chile pos-Concertación: ¿Quo vadis? (pp. 23-35). Santiago, Chile: Friedrich Ebert Stiftung.

-___- (2012). El regionalismo abierto en la política exterior chilena, ¿versión original o concepto equívoco? Revista Enfoques, X (17), 19-31.

Furche, C. (27 de septiembre de 2013). Consultor internacional, Chile. Comunicación personal. Santiago, Chile.

Ley $N^{\circ}$ 18.695, Orgánica Constitucional de Municipalidades. Santiago, Chile, 9 de mayo de 2006. Recuperado de http://www.leychile.cl/Navegar?idNorma=251693

Ley $N^{o}$ 19.175, sobre Gobierno y Administración Regional. Santiago, Chile, 5 de noviembre de 1992. Recuperado de http://www.leychile.cl/Navegar?idNorma $=30542$

Ley $N^{o}$ 19.300, sobre Bases Generales del Medio Ambiente. Santiago, Chile, 1 de marzo de 1994. Recuperado de http://www.leychile.cl/Navegar?idNorma=30667

Lijphart, A. (1991). Las democracias contemporáneas. Barcelona, España: Ariel.

MacShane, D. (6 de junio de 2003). La nueva política interméstica. Diario ABC.

Maira, L. (8 de noviembre de 2013). Investigador y consultor académico, México. Comunicación personal. Santiago, Chile.

Muñoz Gomá, O. (2007). El modelo económico de la Concertación 1990-2005. ¿Reformas o cambio? Santiago, Chile: FLACSO-Catalonia.

Muñoz, H. (1986). Las relaciones exteriores del gobierno militar chileno. Santiago, Chile: PROSPEL-CERC / Las Ediciones del Ornitorrinco. 
Ominami, C. (2 de octubre de 2013). Presidente honorario Fundación Chile 21. Comunicación personal. Santiago, Chile.

Pizarro, R. (16 de septiembre de 2013). Consultor económico internacional. Comunicación personal. Santiago, Chile.

Pochmann, M. (1 de octubre de 2009). Crisis de 1929, ochenta años después. Diario Valor Económico, Sao Paulo, Brasil.

Portales, C. (2011). La (re)construcción de la identidad internacional de Chile: la política multilateral de la Concertación (1990-2010) y los nuevos desafíos para la política exterior. Working paper ICSO-UDP. Recuperado de http://www.icso.cl/wp-content/ uploads/2012/01/Working-Paper-ICSO-Taller-4..pdf

Reniu, J. M. y Albala, A. (2012). Los gobiernos de coalición y su incidencia sobre los presidencialismos latinoamericanos: el caso del Cono Sur. Revista de Estudios Políticos, 26, 162-214. Recuperado de http://www.scielo.org.mx/scielo.php?pid=S0185$16162012000200008 \&$ script=sci_arttext

Renouvin, P. y Durosselle, J. P. (2000). Introducción a la historia de las relaciones internacionales. Ciudad de México, México: Fondo de Cultura Económica.

Van Klaveren, A. (17 de junio de 2013). Representante de Chile ante la Corte Internacional de Justicia, por el diferendo sobre los límites marítimos con la República del Perú. Comunicación personal. Santiago, Chile.

Verdugo, M., Pfeffer, E. y Nogueira, H. (1993). Manual de Derecho Constitucional. Tomo II. Santiago, Chile: Editorial Jurídica de Chile.

Wilhelmy, M. y Durán, R. (2003). Los principales rasgos de la política exterior chilena entre 1973 y el 2000. Revista de Ciencia Política, XXIII (2), 273-286.

Williamson, J. (1989). What Washington Means by Policy Reform. Washington D.C., Estados Unidos: Institute for International Economics. 